MasLina LJUBičić

FILOZOFSKI FAKULtet SVEUČILIŠTA U ZAGREBU

ZAGREB, HRVATSKA

mljubici@ffzg.hr

https://doi.org/10.17234/9789531755139.18

\title{
LEKSEM RIBA U FRAZEOLOGIJI HRVATSKOGA I DRUGIH EUROPSKIH JEZIKA
}

\begin{abstract}
Leksem riba od davnine je zastupljen u frazeologiji hrvatskoga i drugih europskih jezika. U ovome nam je radu cilj analizirati nekoliko takvih frazema. Izvor im nerijetko otkrivamo u poslovicama. Kako vrlo često vuku podrijetlo iz starogrčkoga i latinskoga, obraćamo pozornost na njihovu zastupljenost u zbirci „Adagiorum chiliades“ Erazma Roterdamskoga, u kojoj su latinske poslovice, izreke i frazemi objašnjeni i oprimjereni navodima iz djela grčkih i rimskih pisaca i Biblije. Ta je zbirka svjedočanstvo europske paremiološke i frazeološke tradicije, a mogla je poslužiti i kao poticaj za širenje poslovica i frazema u europske jezike. Osim frazema s leksemom riba, u analizu je uključen i izraz loviti u mutnom, s glagolom koji je u većini jezika izveden od leksema riba, a često se upotrebljava u prenesenome značenju (npr. fr. pêcher la nouvelle, tal. pescare le informazioni, njem. die Information auffischen).
\end{abstract}

Ključne riječi: leksem riba, frazem, poslovica, hrvatski jezik, drugi europski jezici

\section{Uvod}

Kako je čovjek vezan za vodu i velikim dijelom iz nje crpi hranu, ribe i druga vodena stvorenja vrlo su mu bliska. Njima konceptualizira svijet i svoje djelovanje. Stoga nas ne čudi da su hidrozoonimi, posebice talasozoonimi, zastupljeni u frazeologiji kako hrvatskoga tako i drugih europskih jezika. Navest ćemo dva primjera uporabe vrlo ekspresivnih frazema koje susrećemo u 16. stoljeću, u komedijama „Arkulin“ i „Dundo Maroje“ Marina Držića. Riječ je o frazemima koji nedvojbeno doprinose slikovitosti govora Držićevih likova. Izgovaraju ih Arkulin i Popiva, koji vrlo dobro znaju kako se lovi oborita riba. Arkulin kaže: Kurvina kćeri, er bi za mnom trčala, a ja bih prid tobom bježao, ter bih te morio kako ovratu na tri dlake, kako sad i ti mene moriš (Držić 1999: 324). U navedenome frazemu Arkulin spominje stari način lova na ovratu (tj. oradu ili komarču, vrlo kvalitetnu ribu): moriti ovratu na tri dlake znači umarati, pri lovu, tu ribu vukući i popuštajući povraz spleten od tri strune konjskoga repa kako bi se napokon umornu ribu izvuklo iz mora. ${ }^{1} \mathrm{U}$ „Dundu Maroju“ Popiva na kraju replike koju prenosimo slikovito govori o lukavoj rimskoj kortižani koja je malo uložila da bi puno dobila: Komu bi ovo išlo od ruke - rimskoj kortižani izet dukate iz ruke, izet joj srce iz tijela?! Dobro prođe: lakomos lakomosti dobismo! Ova je stavila na udicu nariklu za izet smuduta (id.: 201). ${ }^{2}$

Prema tumačenju Frana Čale (usp. Držić 1999: 324, bilj. 18).

2 Tj. stavila je na udicu morskoga pužića da bi izvukla smuduta. Smudut je osobito cijenjena riba (drugi nazivi: lubin, brancin), a narikla je morski pužić koji se drugdje zove nanar(a). 
Ihtionimi i malakonimi od davnine su zastupljeni u frazeologiji i vrlo se često prenose iz jednoga jezika u drugi. Belostenec u svome Gazofilaciju (I, 329) pod natuknicom concha ('školjka') navodi izraze concha dignus nekay, ale mikay vreden ${ }^{3} \mathrm{i}$ conchas legere vreme trofjiti, ili gubiti. Otkrivamo da je izraz concha dignus ("školjke dostojan") ${ }^{4}$ Erazmo Roterdamski zabilježio u zbirci „Adagiorum chiliades”. Riječ je o prijevodu izraza

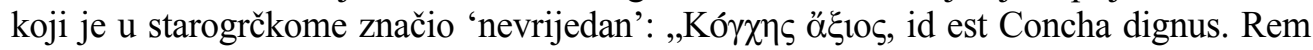
nullius pretii concham dicunt Graeci, quemadmodum Latini nauci aut floccum. Unde quod

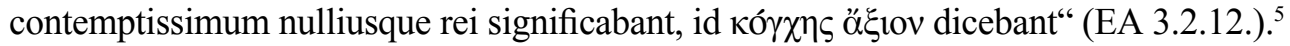

U hrvatskim je primorskim govorima velik broj frazema koji sadrže hidrozoonime, mahom ihtionime. U djelima naših starih pisaca zabilježen je velik broj poredbenih frazema. Primjerice, u Pjesanci spurjanom iz 16. stoljeća pojavljuje se pužljiv kakono jegulja (Kekez 1990: n. 180). ${ }^{6}$ U Daničićevoj zbirci poslovica nalazimo Izmiče se kako jegulja i Nije ga za što uhitit’: izmiče se kako jegulja (Daničić 1871: 1297 i 3013). Klasični predložak ovoga frazema nalazimo u Plautovoj komediji „Pseudolus“ (2, 4, 56), u kojoj je za jegulju vezan semantizam 'klizavost, izmicanje': Anguilla est, elabitur ("Jegulja je, izmiče"). Hiperonim riba zabilježen je u poredbenome frazemu biži brzo kako riba (Kekez 1990: n. 122). Tekst s kraja 18. stoljeća sadrži vrlo ekspresivan frazem trese se ko riba na ostima (id.: n. 1330). ${ }^{7} \mathrm{U}$ ovome nam je radu cilj analizirati nekoliko frazema s leksemom riba koje nalazimo u hrvatskome i drugim europskim jezicima. Da bismo ustanovili vuku li korijen iz grčko-latinske tradicije, potvrdu ćemo potražiti u zbirci „Adagia“ Erazma Roterdamskoga, koja predstavlja velik paremiološki i frazeološki korpus. ${ }^{8}$ Završno izdanje Erazmove zbirke, tiskano 1536. godine, sadrži 4151 poslovicu, izreku ili frazem, koji su objašnjeni i oprimjereni navodima iz djela klasičnih pisaca i Biblije.

\section{Frazemi s leksemom riba}

2.1. Hrvatski frazemi s leksemom riba, kao i njima istovjetni u brojnim drugim europskim jezicima, vrlo često vuku podrijetlo iz starogrčkoga. Kao primjer može nam poslužiti poredbeni frazem nijem kao riba ili šuti kao riba. Belostenec (I, 921, s. v. piscis)

3 U hrvatskim navodima iz Belostenčeva rječnika čuvamo izvornu grafiju. U Gazofilaciju je pogreškom otisnuto mikay umjesto nikay (lat. nihil).

4 U dvostruke navodnike pišemo doslovni prijevod.

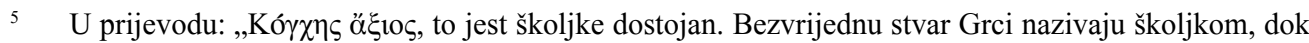
Latini to nazivaju orahovom ljuskom ili pramičkom. Stoga su za ono što su smatrali vrlo neznatnim i

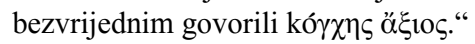

6 U Pjesanci spurjanom Mavra Vetranovića čitamo oblik pužljiva, kako no jegulja. Usp. tal. come un'anguilla, essere un anguilla (Pittàno 1992: 107).

7 Navodimo inačice treptiš kao riba na ostima (Šimunković 2005: 116) i u govoru Šepurine drče (drhti) kaj riba na ostima (Kursar 1982: 139).

8 „Adagia“ jest uobičajen naziv Erazmove zbirke. Erazmo Roterdamski (pravo ime Geert Geerts, lat. pseudonim Desiderius Erasmus Roterodamus) tiskao je u zbirci „Adagiorum collectanea“ (Pariz, 1500.) 818 latinskih poslovica i izreka popraćenih filološkim komentarima. U izdanju iz 1505. godine nešto ih je više, 838. Počevši od venecijanskoga izdanja iz 1508. godine, u kojemu se broj penje na 3260, Erazmo uvrštava u zbirku brojne grčke citate i naslovljuje je „Adagiorum chiliades”. 
prevodi lat. magis mutus qvam piscis - hrv. chifzto tih, mucheh. ${ }^{9}$ Latinski izraz s imenicom piscis u množini (magis mutus, quam pisces "njemiji od riba") Erazmo je uvrstio u „Adagia“. Riječ je o izrazu s pridjevom u komparativu koji postoji i u starogrčkome,

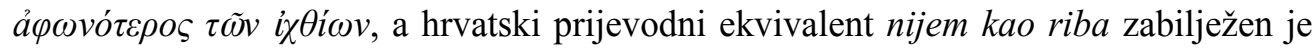
u Sencovu grčko-hrvatskom rječniku (1910: 455). Erazmo objašnjava: „Аф

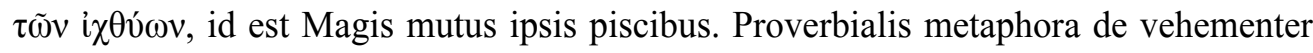
infantibus atque infacundis. Conveniet et in hominem immodicae taciturnitatis" (EA 1.5.29.). ${ }^{10}$ Ovaj frazem nedvojbeno je dio europskoga kulturnog nasljeđa. Riba kao simbol šutljivosti javlja se u klasičnih pisaca Horacija, Lucijana i Plutarha te u djelu „Naturalis historia“, u kojemu je Plinije Stariji sakupio većinu znanja svojega vremena (usp. EA 1.5.29.; Piirainen 2012: 512).

U starijoj talijanskoj inačici ovoga frazema, più muto che un pesce ${ }^{11}$, pridjev je u

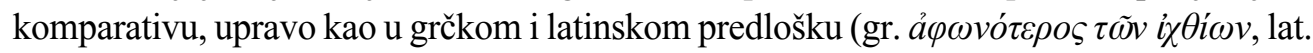
magis mutus, quam pisces/piscis). Noviji je oblik frazema tal. muto come un pesce, s pridjevom u pozitivu kao i u drugim modernim jezicima. U hrvatskom standardnom jeziku i u primorskim govorima postoji više inačica: (biti) nijem kao riba (MVHTF 78), šutjeti kao riba (RHJ 1978), muči ki riba (MFNG 287), muči kao riba (NDPZ n. 760), mucî kako rïba (Deanović 1966: 30). ${ }^{12}$ Slovenski je biti tiho/molčati kot riba, slovački byt' ticho ako ryba / mlčat' ako ryba (PFŽR 27). Prenosimo isti frazem iz još nekoliko jezika:

tal. (essere) muto come un pesce (Pittàno 107)

šp. $\quad$ callado como un pez (Piir. 512)

rum. $\quad$ mut ca un peşt (Piir. 512)

arum. $\quad$ amutsã ca pescu (Piir. 512)

eng. $\quad$ as mute as a fish (Piir. 512)

njem. $\quad$ stumm wie ein Fisch (sein) (WDI 351)

latv. mèms kā zivs (Piir. 512)

ruski нем как рыба (Piir. 512)

češki němýjako ryba (Fronek 1061)

polj. niemy jak ryba (Piir. 512)

mak. нем како риба (Piir. 512)

bug. мълча като риба (Piir. 512)

mađ. néma, mint a hal (Piir. 512)

finski olla mykkä kuin kala (Piir. 512)

eston. $\quad$ tumm nagu kala (Piir. 512)

\footnotetext{
$\overline{9} \quad$ Trebalo bi stajati muchech (izgovor: mučeć), kao što je napisano u hrvatsko-latinskom dijelu Gazofilacija (navedeni latinski ekvivalenti: taciturnus, silentiarius, tacitus, silens).

10 U prijevodu: „A vrlo nerječite i nevješte govoru. Vrijedi i za pretjerano šutljiva čovjeka“.

11 Datirano prije 1520. god., usp. Cortelazzo i Zolli 1999: 1176.

12 Postoji i muči kako i trp (Šimunković 116).
} 
2.2. U zbirci „Adagia“ nalazimo i latinski izraz neque caro neque piscis (doslovno: ni meso ni riba), kojemu odgovara hrvatski ni riba ni meso. Erazmo tumači značenje: „dicunt hodie neque caro est neque piscis, de homine qui sibi vivit nec ullarum est partium“ (EA 4.5.44.). ${ }^{13}$ Taj se frazem u inačicama pojavljuje u velikome broju europskih jezika:

lat. neque caro neque piscis esse (Arth. 1068)

tal. $\quad$ non essere né carne né pesce (LDMD 55)

fr. $\quad$ n'être ni chair ni poisson (Arth. 1068)

šp. $\quad$ no ser carne ni pescado (Arth. 1068)

port. não ser carne nem peixe (DLP 1263)

nj. $\quad$ weder Fisch noch Fleisch sein (Arth. 1068); nicht Fisch noch Fleisch $(\mathrm{HNjFR} 653)^{14}$

eng. $\quad$ to be neither fish, nor flesh, nor fowl (Arth. 1068); neither fish, flesh nor fowl (Gull. 73); neither fish nor flesh, nor good red herring (Arth. 1068); neither fish, flesh, fowl nor good red herring (Gull. 73) $)^{15}$

mađ. $\quad$ se hús, se hal (PWUD 545)

ruski ни рыба ни мясо (PRDDR 153)

hrv. ne biti ni riba ni meso (HNjFR 489)

češki ani ryba ani rak (Fronek 1061)

Osim ni riba ni meso, u hrvatskome postoji semantički ekvivalentan frazem s nazivima riba: ni pirka ni kanjac (usp. Ljubičić i Kovačić 2008: 3.1.-3.1.1.).

2.3. Kad netko izvrsno pliva kaže se da pliva kao riba, a taj se frazem javlja i u metaforičkome značenju (MFNG 287). Poticaj za njegov nastanak bilo je ljudsko iskustvo da se ribe u vodi brzo kreću. Na talijanskom frazem glasi nuota come un pesce, na slovenskom plavati kot riba, na slovačkom plávat' ako ryba (PFŽR 27). Umjesto leksema riba u hrvatskome se s istim značenjem rabi i frazem pliva kao dupin. ${ }^{16} \mathrm{U}$ mletačkome dijalektu Dalmacije nudar come un delfin ('essere nuotatore provetto', Miotto 1984: 72). U rječniku venecijanskoga dijalekta osim nuàr come un pesse zabilježen je i frazem suprotnoga značenja: nuàr come un pesse de piombo o come un'ancora "plivati kao olovna riba ili kao sidro" ('non saper nuotare', Boerio 1856: 445).

$\overline{13}$ U prijevodu: „danas kažu nije ni meso ni riba za čovjeka koji sam za sebe živi i ne opredjeljuje se ni za koju stranu".

14 Usp. poslovicu Halb Fisch, halb Fleisch ist Fisch noch Fleisch: / Gar Fisch ist Fisch, gar Fleisch ist Fleisch. (Simrock 2000: 2476).

15 Inačicu neither fish nor flesh, koja slijedi latinski obrazac, nalazimo u Shakespeareovoj povijesnoj drami „Henrik IV“ (tiskanoj 1596. god.): „Why, she’s neither fish nor flesh; a man knows not where to have her" (Henrik IV, III, 3, 127). Usp. Allen 2008: 285.

16 U govoru Šepurine postoji i roni kaj dupin (Kursar 1982: 139). 
2.3.1. Iz latinskoga potječe izreka učiš ribu plivati (lat. piscem natare doces), koja je česta u talijanskome jeziku: insegnare a nuotare ai pesci. ${ }^{17} \mathrm{Na}$ latinski je ta izreka

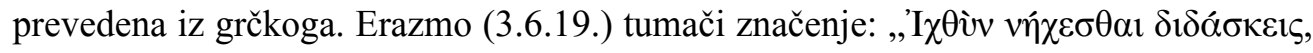
id est Piscem natare doces. Perinde est ac si dicas: Doctum doces“ ${ }^{18}{ }^{18} \mathrm{U}$ oba klasična jezika postoje inačice s leksemom 'dupin': gr. $\Delta \varepsilon \lambda \varphi \tilde{\imath} v \alpha$ v $\{\chi \varepsilon \sigma \theta \alpha l \delta l \delta \alpha ́ \sigma \kappa \varepsilon l \varsigma$ - lat.

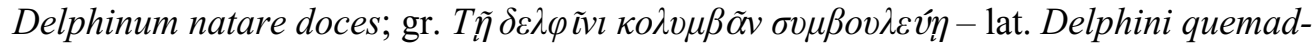
modum natare oporteat consulis (usp. EA 3.6.19. i 1.4.97.). U ruskome postoji Не учи рыбу плавать, a česta je inačica s nazivom ribe, щука 'štuka': Не учи щуку плавать! щука знаеть свою науку (BTFM s. v.). Postoji i varijanta s leksemom $р ы б а$ u kojoj se dodaje da ni psa ne treba učiti lajati: Не учи рыбу плавать, а собаку - лаять (Слов. Акад. s. v.). Prenosimo mletačku poslovicu u kojoj se spominje riba škrpina (tal. pesce scorpena): Xe mato da caena che vol insegnar a nuar a la scarpena (Šimunković 2005: $115)$.

2.3.2. U latinskome postoji ekvivalentna izreka u kojoj se umjesto ribe spominje orao, kojega ne treba učiti letjeti kao što ribu ne treba učiti plivati: Aquilam volare

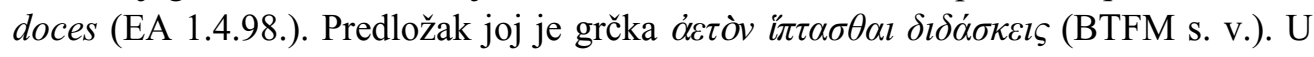
talijanskome se $\mathrm{u}$ istome značenju upotrebljava frazem s hiperonimom uccello 'ptica', a uobičajeni su i frazemi u kojima se spominje gatto 'mačka' (izvrsno se vere) ili lepre 'zec' (izvrsno trči): insegnare agli uccelli a volare, insegnare ai gatti ad arrampicare, insegnare alla lepre a correre.

2.4. Kad se netko dobro osjeća, kad je u svome elementu, kažemo da se osjeća, snalazi ili da je kao riba u vodi. Taj frazem nalazimo u hrvatskome i drugim jezicima. Navodimo ih nekoliko:

hrv. osjećati se (biti, snalaziti se) kao riba u vodi (HNjFR 489, RHJ 1978, MFV 254)

slovenski kot riba v vodi (PFŽR 27)

slovački byt'ako ryba vo vode (PFŽR 27)

tal. $\quad$ sentirsi (essere ecc.) come un pesce in acqua (MVHTF s. v.)

šp. estar como el pez en el agua (Carbonell 1108); como pez en el agua (GDUE 1602)

port. $\quad$ estar como peixe na água (DLP 1263)

njem. $\quad$ sich fühlen (wohlfühlen) wie ein Fisch im Wasser (HNjFR 489)

2.5. Suprotnoga je značenja frazem kao riba na suhom. U engleskome a fish out of water zabilježeno je u 17. stoljeću ('a person who is caught in unfamiliar or unsuitable surroundings or circumstances', Allen 2008: 284). Navodimo primjere ovoga frazema iz nekoliko jezika:

$17 \quad$ Također u negativnom obliku: non voler insegnare ai pesci nuotare (Selene 240).

18 U prijevodu: „' $\chi \chi \vartheta े v ̀ v ~ v \eta ́ \chi \varepsilon \sigma \vartheta \vartheta \alpha \_~ \delta 1 \delta \alpha ́ \sigma \kappa \varepsilon เ \varsigma$, to jest Učiš ribu plivati. To je isto kao da kažeš: Učenoga učišs“. 
hrv. $\quad$ osjećati se (ostati, biti) kao riba na suhu (na suhom) (RHJ 1978; MFV 254)

slovenski počutiti se (biti) kot riba na suhem (PFŽR 27)

slovački byt', citit' sa ako ryba na suchu (PFŽR 27)

tal. sentirsi (essere) come un pesce fuor d'acqua (Quartu 393); essere (sentirsi) un pesce fuor d'acqua (Sorge 178); ven. esser come un pesse fora de mar (Šimunković 115)

njem. $\quad$ sich fühlen wie ein (der) Fisch auf dem Trockenen (HNjFR 489)

eng. $\quad$ to be like a fish out of water (Gull. 73)

U hrvatskim primorskim govorima nalazimo frazem pliva ko riba na suvon 'ne snalaziti se', a u sljedećima su izdvojene slikovite pojedinosti: pobilile mu oči ko ribi na suvon (MFNG 287), puše kao riba na suhu (Gluhonja 286; Županović 161), zivat ka riba na suvu (Ljubičić i Kovačić 2008: 1.6.1.).

2.6. Ribe se u vodi brzo kreću pa je odatle nastao poredbeni frazem pliva kao riba, o kojemu smo govorili, a koji se rabi u doslovnom i prenesenom značenju. Ribe su spretne i okretne kad su u svome elementu - vodi i na temelju te činjenice stvoreni su frazemi kao riba u vodi i kao riba na suhu (suhom). U njemačkome jeziku postoji frazem munter wie ein Fisch im Wasser "živahan kao riba u vodi". ${ }^{19}$ Osim spomenutih, okretnost riba potakla je i nastanak poredbenoga frazema $z$ drav kao riba ${ }^{20} \mathrm{koji}$ se najčešć javlja s glagolom biti: biti zdrav kao riba ('biti posve zdrav'). Postoji i u drugim jezicima, npr. u slovenskom biti zdrav kot riba, u slovačkom byt' zdravý ako ryba (PFŽR 27). U njemačkome se precizira da je riječ o ribi u vodi: gesund wie ein Fisch im Wasser (Arth. 669). U talijanskome, gdje se ovaj frazem rabi češće nego u hrvatskom, osim s leksemom pesce 'riba' (tal. essere sano come un pesce), postoje i inačice s nazivima riba sarago (hrv. sarag) i lasca (hrv. crvenperka): tal. essere sano come un sarago / una lasca (CDMDE n. 1036). Osim zdrav kako riba Daničić (1871: 5804) navodi i zdrav kako pastrvica.

U Boccacciovu „Decameronu“ (IX, 3) čitamo: „Io ti farò fare una certa bevanda stillata molto buona, che in tre mattine risolverà ogni cosa, e rimarrai più sano, che pesce ". ${ }^{21}$ Primjećujemo da je upotrijebljen komparativ più sano che pesce "zdraviji od ribe", dok je danas uobičajen oblik s pridjevom u pozitivu, sano come un pesce "zdrav kao riba". Činjenica da smo se već sreli s grčkim i latinskim frazemom s komparativom (gr.

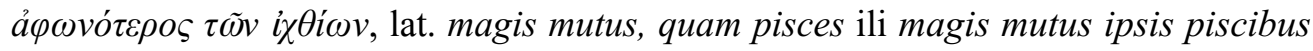
"njemiji od riba"), kojemu i u talijanskom odgovara starija inačica s komparativom (tal.

19 U talijanskoj frazeološkoj istovrijednici govori se o živahnome cvrčku: vispo come un grillo (WDI 351).

20 Inačica u govoru Vrboske na Hvaru: zdrôv ko / kakö rïba (Matković 2004: 260).

${ }_{21}$ U prijevodu (Boccaccio 1981: 556): „Priredit ću ti neki prekuhani napitak, veoma dobar i veoma ukusan za piće, i u tri jutra sve će to proći, i bit ćeš zdraviji od riba“. 
più muto che un pesce), navela nas je na pomisao da je riječ o mogućemu refleksu izraza iz grčko-latinske tradicije. Doista, u Juvenalovu stihu postoji izraz s pridjevom sanus 'zdrav' u komparativu, Sanior es pisce (EA 4.4.93.). Riječ je o starijemu obliku frazema, a mlađi oblik, s pridjevom u pozitivu, ušao je u moderne europske jezike. Erazmo objašnjava: „Proverbialiter haud dubie dixit Iuvenalis: Sanior es pisce. Nam ad eum modum hodieque vulgo loquuntur: Tam sanus es quam piscis" (ib.). ${ }^{22}$

\section{Od poslovice do frazema}

3.1. Premda su poslovice kao izraz narodne mudrosti svojina nekoga naroda, u najvećemu broju slučajeva otkrivamo da ne pripadaju samo jednome narodu. Vrlo često vuku podrijetlo od grčkih i rimskih klasičnih pisaca ili iz Biblije. Uslijed opće uporabe misli pojedinih autora pretvorile su se tijekom vremena u narodne poslovice (usp. Paczolay 1998a). Poslovice postoje u brojnim inačicama. Katkad se navode u kraćemu obliku, dok se ostatak podrazumijeva. Poslovice i frazemi nerijetko su povezani. Izvor frazema često otkrivamo u poslovicama, a na temelju starih poslovica i frazema nastaju nove poslovice.

Frazem kao riba bez vode nalazimo u poslovici u kojoj se redovnik (lat. monachus) izvan samostana uspoređuje s ribom izvan vode ili mora. U varijacijama postoji u više jezika:

(1) lat. Ut piscis extra aquam, sic monachus extra cellam. (Mikić i Škara 242)

(2) hrv. Fratar van ćelije riba je van mora. (Daničić 779; Kekez 108)

(3) tal. ven. Un frate fora del su'convento, el xe com'un pesse fora de su'elemento. (Detoni 36)

(4) njem. Der Fisch gehört ins Wasser, der Mönch ins Kloster. (Mikić i Škara 242)

Navedena latinska i hrvatska poslovica podsjećaju na nelagodu ribe izvan mora, a talijanska (mletačka) (3) govori o ribi izvan svoga elementa. Njemačka poslovica (4) ističe da svatko ima svoje mjesto. Ribi je mjesto u vodi, a redovniku u samostanu. Za razliku od poslovica (1-3), u sljedećoj hrvatskoj (5) nije riječ o nelagodi i nesnalaženju izvan svoga elementa, nego je poruka nešto drugačija: izvan mora riba se lako usmrdi, tj. pokvari, kao i fratar kad nije u samostanu. Španjolska poslovica (6) upozorava da je ribi mjesto u vodi kao što je kovaču mjesto u kovačnici:

(5) hrv. Lasno se usmrde fratar van ćele i riba van mora. (Daničić 1952). ${ }^{23}$

(6) šp. El pez en el agua y el herrero en la fragua. (DDR s. v.)

22 U prijevodu: „Bez sumnje je u obliku poslovice Juvenal rekao: Zdraviji si od ribe. Naime na taj se način i danas obično govori: Zdrav si kao riba“. Erazmo napominje da se tome protivi Aristotel u osmoj knjizi „Istraživanja o životinjama“ i Plinije u devetoj knjizi „Naturalis historia“ (u izvorniku: „Quamquam huic sententiae refragatur Aristoteles libro De natura animalium octavo atque hunc secutus Plinius libro nono", EA 4.4.93.).

23 Usp. tal. puzzare come un pesce (marcio) 'zaudarati kao (trula) riba'. 
Postoje i varijante u kojima je riječ o vuku ili zvijeri koji ne mogu bez šume kao što ne može riba bez vode:

(7) hrv. Riba bez vode, a vuk bez gore bit ne može. (Mikić i Škara 242)

(8) hrv. Ni riba bez vode, ni zvier bez gore. (Mikić i Škara 242)

U nekoliko inačica proširena je i poslovica o slobodi koja je čovjeku potrebna kao ribi voda jer bez nje ne može živjeti:

(9) hrv. Čovjek bez slobode, kao riba bez vode. (Skarpa 393)

(10) hrv. Gradišće - Človik prez slobode je kot riba prez vode. (Schoretits i Probst 74)

(11)hrv. Bez narodne (domaće) slobode, kao riba bez vode. (Skarpa 393)

3.2. Kao što je rečeno, frazem može nastati od poslovice. Primjerice, izraze velika/ krupna riba ('važna, moćna osoba') i mala/sitna riba ('nevažna osoba') povezujemo s poslovicom Velika riba jede malu ('moćni uništavaju, gutaju slabe'). U Belostenčevu rječniku latinska poslovica Saepe minutos pisces magnus comest prevedena je na hrvatski: Menfe ribicze gufche vekfa pojeda. Nalazimo je u brojnim inačicama u velikom broju jezika. Prenosimo iz raznih izvora:

(12) lat. Piscem vorat maior minorem. (Arth. 1069)

(13) lat. Pisces minutos magni comedunt. (Gibbs 145/1874)

(14) lat. Pisces magni parvulos comedunt. (ib.)

(15) lat. Piscis saepe minutos magnus comest. (PLT s. v.)

(16) lat. Magnus piscis minutos comest. (PLT s. v.)

(17) lat. Saepe minutos pisces magnus comest. (Belostenec I, 314)

(18) tal. Il pesce grosso mangia il piccolo. (Selene 229)

(19) tal. Il pesce grosso mangia quello piccolo. (PMP s. v.)

(20) tal. Il pesce grosso divora il piccolo. (Bogg.Mass. VIII.3.1.35.I.)

(21) tal. Il pesce grosso divora il pesce piccolo. (Bogg.Mass. VIII.3.1.35.III.)

(22) tal. Il pesce grosso mangia il minuto. (Lap.prov. P 1419)

(23) tal. Il pesce grosso inghiotte il minuto. (Bogg.Mass. VIII.3.1.35.IV.)

(24) tal. Il pesce grosso mangia il più piccino. (Bogg.Mass. VIII.3.1.35.VI.)

(25) tal. Il pesce grosso si pappa il piccolo. (Bogg.Mass. VIII.3.1.35.II.)

(26) tal. I pesci grossi mangiano i piccini. (Bogg.Mass. VIII.3.1.35.V.)

(27) tal. I pesci grossi ingoiano i minuti. (Bogg.Mass. VIII.3.1.35.VII.)

(28) tal. I pesci grandi mangiano i piccoli. (Bogg.Mass. VIII.3.1.35.VIII.)

(29) tal. Ipesci grossi mangiano quelli piccoli. (Lap.prov. P 1418)

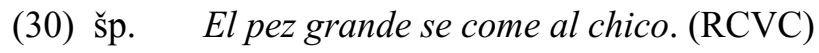

(31) šp. El pez grande se come al pequeño. (RCVC)

(32) šp. Los peces grandes se tragan los menores. (RCVC)

(33) šp. Los peces mayores se tragan los menores. (Arth. 1069)

(34) fr. Les gros poissons mangent les petits. (RCVC) 
(35) port. Peixe grande come peixe pequeno. (RCVC)

(36) baskijski Arrain handiak jaten ditu txipiak. (RCVC)

(37) njem. Große Fische fressen die kleinen. (RCVC)

(38) eng. Big fish eat little fish. (PDP 81/43) ${ }^{24}$

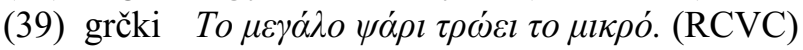

(40) hrv. Menfe ribicze gufche vekfa pojeda. (Belostenec I, 314)

(41) hrv. Riba velika ije ribu malu. (Daničić 8953)

(42) hrv. Vele ribe male jidu. (NDPZ n. 449)

(43) hrv. Velike ribe male proždiru. (Mikić i Škara 243)

(44) hrv. Veća riba manju jede. (Mikić i Škara 243)

(45) hrv. Mali Iž Vela riba malu î. (Jelić 95)

(46) hrv. Gradišće Velike ribe male jidu. (Schoretits i Probst 75)

(47) hrv. Nije nigda mala riba izjela veliku. (Šimunković 115)

(48) slovenski Velike ribe male žro.

(49) ruski Большая рыба маленькую иеликом глотает. (RCVC)

U španjolskom postoji dulja inačica (50), u kojoj se eksplicira značenje, tj. kaže se da bogataši gutaju siromašne. Zanimljivo je da se u talijanskoj (51) umjesto "velika riba" i "mala riba" navode imena riba luccio 'štuka' i tinca 'linjak'. Evo tih inačica:

(50) šp. El pez grande se come al chico, y asi al pobre el rico. (RCVC)

(51) tal. Il luccio mangia la tinca. (Bogg.Mass. VIII.3.1.35.X.)

3.2.1. Metafora velikih riba suprotstavljenih malima potječe iz antičkih vremena. Marko Terencije Varon (116. pr. Kr. - 27. pr. Kr.) izrazio je u elegijskom distihu misao da velika riba jede malu: qui pote, plus urget, piscis ut saepe minutas / magnu' comest (ANRW 39). Ta se misao oblikovala u poslovicu, a ova se prenosila preko patrističke književnosti i propovijedi (Cortelazzo i Zolli 1999: 1178). Paremiolog Gyula Paczolay (1998) navodi da postoji u 37 od 55 europskih jezika koje je istražio.

3.2.2. Česti su frazemi s glagolom biti: hrv. biti krupna riba ${ }^{25}$, biti sitna riba ${ }^{26}$. U engleskome se izrazi a big fish i a little fish javljaju u poznatoj poslovici (52) koja kaže da je bolje biti krupna riba u maloj bari, nego mala riba u velikoj bari:

(52) engl. Better a big fish in a little puddle than a little fish in a big puddle. (Sevilla Muñoz 360)

24 Usp. iz Shakespeareova teksta (Pericles, II, 1): „I marvel how the fishes live in the sea. - Why, as men do a-land; the great ones eat up the little ones“" (Arth. 1069).

25 Također španjolski ser un pez gordo (DDR s. v.).

26 Njem. ein kleiner Fisch (sein) (Schemann 2000: 52). Drugačije je značenje frazema [das sind] kleine Fische "[das sind] Dinge, die nicht ins Gewicht fallen; Kleinigkeiten" (RWDI 228). 
Postoje brojni ekvivalenti ove poslovice u raznim jezicima. ${ }^{27}$ Izdvajamo španjolsku (53) s leksemom pez 'riba' ("Više vrijedi biti u selu glava inćuna, nego u velikome gradu rep krupne ribe"):

(53) šp. Más vale en aldea ser cabeza de boquerón, que en gran ciudad cola de pez mayor. (Sevilla Muñoz 360) ${ }^{28}$

Sintagmi cola de pez mayor ("rep krupne ribe" - frazeološki ekvivalent engleskoga little fish in a big puddle) semantički je oprečna cabeza de boquerón ("glava inćuna", tj. male ribe - frazeološki ekvivalent engleskoga big fish in a litte puddle). Navodimo hrvatsku ekvivalentnu dijalektalnu poslovicu u kojoj se govori o glavi nevrijedne ribe gire nasuprot repu cijenjene vrste, cipla:

(54) hrv. Bolje je biti glava od gere, nego kuda od cipola. (Šimunković 120)

U engleskom je od poslovice (52) Better a big fish... nastao frazem a big fish in a small/little pond. ${ }^{29}$ Prenosimo primjere uporabe engleskoga frazema a big fish (in a little pond) u kojima se jasno upućuje na poslovicu iz koje je nastao: „They are big fish in a little pond, but one has seen plenty of them shrink... when they have been plunged into the London 'big water'.“..., Was he just a big fish in a very small pool?“ (Allen 2008: 284).

3.3. Vrlo je proširen frazem loviti u mutnom ('nastojati iskoristiti nejasnu situaciju da bi se izvukla neka korist'), u hrvatskom s glagolom općega značenja 'loviti', dok se u velikom broju jezika pojavljuje glagol 'loviti ribu', tvorbeno povezan s leksemom 'riba', koji se upotrebljava i u prenesenome značenju (npr. fr. pêcher la nouvelle, tal. pescare le informazioni, njem. die Information auffischen). Frazem loviti u mutnom povezujemo s poslovicom koja vuče korijen od starogrčkih pisaca. U Belostenčevu hrvatsko-latinskome rječniku hrvatskoj poslovici (55) odgovara latinska (56). Prenosimo ih, kao i još nekoliko latinskih inačica te poslovice iz više europskih jezika:

(55) hrv. Koi love v-mutnoy vode, vszakojachkeh rib nahode.

(Belostenec II, 572-573)

(56) lat. In turbido, piscandum. (ib.)

(57) lat. Aqua turbida piscosior est. (Piir. 53)

(58) lat. Est captu facilis turbata piscis in unda. (Arth. 1362)

(59) lat. Quoniam in aqua turbida piscantur uberius. (Singer 28)

(60) lat. Piscatur in aqua turbida. (Taylor)

$27 \quad$ Poznata je Cezarova izreka Melius in oppidulo esse primum, quam in civitate secundum.

28 Ova je poslovica u španjolskom rjeđa od ekvivalentne, u kojoj se također pojavljuju zoonimi: Más vale ser cabeza de ratón que cola de león (Carbonell 264) i inačice Antes cabeza de ratón, / Que cola de león (Arth. 793).

29 Za engleski frazem i primjere uporabe usp. Gulland i Hinds-Howell 2002: 73; Allen 2008: 284. 
(61) lat. Isti sunt sicut piscatores qui turbant aquam ut possint melius capere pisces. (Singer 29)

(62) lat. Ubi quieta stat palus, nil piscium reportant. (EA 3.6.79.)

(63) lat. Flumen confusum reddit piscantibus usum. (Singer 30)

(64) tal. Acqua torbida è buona per i pescatori. (Selene 308)

(65) tal. bresc. Aqua trubbia, pes en giro. (Arth. 1362)

(66) tal. A fume torbido, guadagno di pescatore. (Bogg.Mass. II.12.2.2.)

(67) tal. Fiume mosso, guadagno di pescatore. (Bogg.Mass. IX.15.3.9.c.I.)

(68) fr. L'eau trouble est le gain du pêcheur. (RCVC)

(69) fr. Eau trouble, gain du pêcheur. (Arth. 1362)

(70) fr. Pêcher en eau trouble / Est gain triple ou double. (Arth. 1066)

(71) fr. Il n'est que pêcher en eau trouble. (Arth. 1362)

(72) šp. Río revuelto da provecho a los que pescan. (RCVC)

(73) šp. Río revuelto, ganancia de pescadores. (Arth. 1066)

(74) šp. $\quad$ En el agua turbia hace buen pescar. (Arth. 1362)

(75) port. Na água revolta, pesca o pescador. (RCVC)

(76) njem. In trübem Wasser ist gut fischen. (Arth. 1362)

(77) njem. Im Trüben ist gut fischen. (Arth. 1066)

(78) njem. In trüben (stillen) Wassern ist gut fischen. (RCVC)

(79) engl. It is good/best/easy/easiest fishing in troubled waters. (Pacz. 55L 391)

(80) engl. It is good fishing in muddy waters. (Taylor)

(81) mađ. (A) zavarosban könnyebb halászni. (RCVC)

Paczolay (2002: 391) kao izvor ove poslovice spominje Aristofana (449.-385. pr. $\mathrm{Kr}$.), a Taylor (1996) smatra da je vjerojatno najstariji zapadni izvor latinsko djelo „De nugis curialium“ Waltera Mapa (rođen 1140., umro između 1208. i 1210.). Singer (1995: 275) prenosi srednjovjekovnu latinsku izreku: Vulgo enim dicitur: Aqua turbida piscosior est ("Narod kaže: U mutnoj vodi ima više ribe"). Ezop (6. st. pr. Kr.) u jednoj basni govori o ribaru koji je lovio ribu udarajući štapom po vodi te ju je mutio. Taylor (1996) iznosi da je latinska poslovica zabilježena u zbirci Petrusa Godofredusa, tiskanoj 1555. godine, da su poslovice iz te zbirke dodane u kasnija izdanja „Adagia“pa poslovicu (60) Piscatur in aqua turbida nalazimo u pariškome izdanju iz 1579. godine. No, valja reći da u zbirci koju je sastavio sam Erazmo postoji izraz anguillas captare ("loviti jegulje”) s komentarom koji govori o lovu u mutnoj vodi (,cum aqua stat immota, nihil capiunt, qui captant anguillas, cum vero sursum ac deorsum miscent ac perturbant aquam, ita demum capiunt "),${ }^{30}$ te o uporabi u prenesenome značenju (EA 3.6.79.). Otkrivamo da latinska poslovica (58) Est captu facilis turbata piscis in unda ima inačicu u kojoj se umjesto piscis pojavljuje leksem anguilla:

(82) lat. In turbida aqua otpima est anguillae captura. (Arth. 1362)

30 U prijevodu: „kad je voda nepomična, ništa ne ulove oni koji love jegulje, a kad vodu gore-dolje izmiješaju i prevrnu, tad je istom ulove“. 
3.3.1. Paczolay (1998: 2002) navodi da ova poslovica postoji u 38 od 55 europskih jezika koje je istražio. Piirainen (2012: 53) objašnjava da je u srednjemu vijeku latinski prijevod Ezopove basne o ribaru koji je mutio vodu pridonio širenju kasnije nastaloga frazema, a bile su vrlo poznate i ilustracije te Ezopove basne flamanskoga slikara Pietera Breughela Starijega. Navodimo latinski frazem, a primjere iz jednoga dijela europskih jezika prenosimo iz knjige Elisabeth Piirainen (2012: 460-463):

lat. piscari in turbido (PLT s. v.)

fr. $\quad$ pêcher en eau trouble (Piir. 461); pêcher en eau troublée (Arth. 1066)

prov. pesca à la treboulino (Piir. 461)

tal. pescare in acque torbide (Piir. 462); pescare nel torbido (Arth. 1066)

šp. $\quad$ pescar en rio revuelto (Piir. 462); pescar a rio revuelto (Arth. 1066)

katal. $\quad$ pescar en aigua tèrbola (Piir. 462)

port. pescar em águas turvas (Piir. 462)

rumunjski a pescui în ape tulburi (Piir. 461); a pescui în apă tulbure (RCVC)

dan. fiske i rørte vande (Piir. 461)

švedski fiska i grumligt vatten (Piir. 460)

eng. $\quad$ to fish in troubled/muddy waters (Piir. 460)

niz. in troebel water vissen (Piir. 461)

njem. im Trüben fischen (Piir. 461)

ruski ловить рыбу в мутной воде (Piir. 462)

ukrajinski ловити рибу в мутній воді (Piir. 462)

češki lovit v kalných vodách (Piir. 462)

slovački lovit'v mútnych vodách (Piir. 462)

polj. $\quad$ towić ryby w mętnej wodzie (Piir. 462)

slovenski ribariti v kalnem (Piir. 462)

hrv. loviti u mutnom (Piir. 462)

maked. лови во матно (Piir. 462)

bug. ловя риба в мътна вода (Piir. 462)

alb. peshkon në ujë/ujëra të turbullt (Piir. 462)

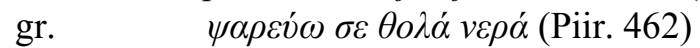

mađ. a zavarosban halászik (Piir. 462)

fin. kalastaa/kalastella sameassa (Piir. 462)

eston. $\quad$ sogases vees kalu pü̈̈ma (Piir. 462)

esperanto fiskkapti/fisii en malklara akvo (Piir. 463)

3.3.2. Osim loviti u mutnom, i sam glagol mutiti 'činiti mutnim' može imati preneseno značenje 'činiti nejasnim; izvoditi nejasne radnje radi dobiti, povećanja utjecaja u društvu ili drugih neposrednih probitaka’, a sinonim mu je muljati. Metafora koja polazi od semantizma 'mutež' i 'muljanje' vrlo je živa te je u hrvatskome potakla nastanak složenica mutikaša, mutivoda i vrlo ekspresivnih izvedenica sa stranim sufiksima: muljator (od kojega je izveden pridjev muljatorski) i muljaža. I od glagola mućkati 'baviti se nedoličnim radnjama, zaobilaziti pravila, propise i zakone', koji je bliskozna- 
čan glagolima mutiti i muljati, izveden je pogrdan naziv mućkaroš za onoga koji živi, zarađuje na brz, mahom nelegalan način. Imenica mućka također se u žargonu odnosi na snalaženje u mutnim poslovima radi brze zarade. Glagol mutiti u prenesenome značenju vrlo se često javlja u frazemu mutiti vodu. Slično je i u drugim jezicima. Primjerice, u engleskome glagol to muddy može značiti 'to confuse or obscure', a frazem to muddy the waters 'to confuse the issue by introducing complications or irrelevancies'. ${ }^{31}$

\section{Zaključak}

Ljudima su dobro poznata stvarna svojstva riba, ali i mitovi o njima i stereotipizirane slike i simboli. Analizirali smo nekoliko frazema s leksemom riba koji postoje u hrvatskome i drugim europskim jezicima. Kad je riječ o frazemima pliva kao riba (inačica pliva kao dupin) ili biži brzo kako riba, svakodnevno je iskustvo moglo dovesti do njihove tvorbe. Za razliku od ovih frazema koji su mogli nastati poligenezom, tj. na temelju istovjetnoga iskustva nezavisno u različitim jezicima, otkrivamo da je nerijetko pojedini frazem potekao iz jednoga izvora, odakle se zatim proširio prevođenjem. Kao jedan od sekundarnih izvora mogla je poslužiti zbirka „Adagia“ Erazma Roterdamskoga, u kojoj su latinske poslovice i izreke objašnjene i oprimjerene navodima iz djela antičkih pisaca. Frazemi se prenose iz jednoga jezika u drugi, vrlo često nezavisno od primarnoga izvora, ili sekundarni izvor može pojačati njihovu uporabu. Primjerice, premda je frazem o lovu u mutnom postojao u latinskome (piscari in turbido), smatra se da je talijanski pescare nel torbido kalkiran prema francuskome pêcher en eau trouble (Cortelazzo i Zolli 1999: 1178).

Istraživanje frazeologije nezamislivo je bez poznavanja kulture (Dobrovol'skij i Piirainen 2006). Frazemi nijem kao riba ili šutjeti kao riba dio su europskoga kulturnog nasljeđa jer se riba kao simbol šutljivosti javlja u Horacija, Lucijana i Plutarha te u „Naturalis historia“ Plinija Starijega. Frazemi često nastaju iz poslovica, a poslovice nerijetko vuku korijen iz djela grčkih i rimskih pisaca i Biblije. Poznavanje Ezopove basne o ribaru koji je mutio vodu pojašnjava poslovicu iz koje je nastao frazem o lovu u mutnom. Zastupljenost analiziranih frazema s leksemom riba u Erazmovoj zbirci svjedoči o njihovoj pripadnosti grčko-latinskoj tradiciji, odnosno europskome kulturnom krugu.

$\mathrm{Na}$ kraju, u vezi s poslovicama iz kojih nastaju frazemi korisno je spomenuti kako, prema rezultatima istraživanja paremiologa Gyule Paczolaya (1998: 2002), razmjerno velikom broju europskih poslovica odgovaraju bliske inačice u orijentalnim jezicima. U takvim je slučajevima riječ o istovjetnome iskustvu. Iz podudarne konceptualizacije mogu nastati i podudarni frazemi. U pogledu frazeologije koja prelazi europske granice posebno je značajan uspješno izvedeni projekt Elisabeth Piirainen Widespread Idioms in Europe and Beyond (Piirainen 2012).

$31 \quad$ Ilustrativan je engleski primjer iz knjige Enocha Powella (Reflections of a Statesman, 1991): „I know as a politician that when you are doing something naughty, nothing is more effective than to muddy the waters with complication. What you fear most is an opponent who will point to a few simple but undeniable facts“. (preneseno iz Allen 2008: 497). 


\section{LITERATURA}

Aufstieg und Niedergang der römischen Welt / Rise and Decline of the Roman World. Geschichte und Kultur Roms im Spiegel der neueren Forschung. 1972. Haase, Wolfgang; Temporini, Hildegard (red.). Berlin - New York: Walter de Gruyter. [ANRW]

Boccaccio, Giovanni. 1981. Djela. Knjiga prva. Dekameron. Prev. Jerka Belan i Mate Maras. Priredili Frano Čale i Mate Zorić. Zagreb: Sveučilišna naklada Liber - Nakladni zavod Matice hrvatske.

Deanović, Mirko. 1966. Lingvistički atlas Mediterana II. Anketa na Visu (Komiži). Rad JAZU. Odjel za filologiju. Knj. 14: 5-35.

Dobrovol'skij, Dmitrij; Piirainen, Elisabeth. 2006. Cultural knowledge and idioms. International Journal of English Studies. Vol. 6 (I): 27-41.

Držić, Marin. 1999. Drame. Klasici hrvatske književnosti. III. Drama i kazalište [CD-ROM]. Zagreb: Bulaja naklada.

Gluhonja, Ivo. 1964. More u našim poslovicama. Naše more. 5: 283-287.

Jelić, Roman. 1987. Pabirci iz govora Maloga Iža. Čakavska rič. God. XV. Broj 2: 83-112.

Kekez, Josip. 1990. Svaki je kamen da se kuća gradi. Osijek: Izdavački centar „Revija“ Otvorenoga sveučilišta.

Kursar, Ante. 1982. Iz leksike i tradicije šepurinskih ribara. Čakavska rič. God. X. Broj 1-2: 97144.

Ljubičić, Maslina; Kovačić, Vinko. 2008. Alcuni ittionimi nella fraseologia croata. U: Lenguaje figurado y motivación. Una perspectiva desde la fraseología. María Álvarez de la Granja (red.). Frankfurt am Main: Peter Lang. 191-207.

Menac-Mihalić, Mira. 2005. Frazeologija novoštokavskih govora u Hrvatskoj s rječnikom frazema i značenjskim kazalom s popisom sinonimnih frazema. Zagreb: Institut za hrvatski jezik i jezikoslovlje - Školska knjiga. [MFNG]

Narodne drame, poslovice i zagonetke. 1963. Bonifačić Rožin, Nikola (red.). Pet stoljeća hrvatske književnosti. Zagreb: Matica hrvatska - Zora. [NDPZ]

Paczolay, Gyula. 1998. European Proverbs. U: Europhras 95: Europäische Phraseologie mi Vergleich. Gemeinsames Erbe und kulturelle Vielfalt. Eismann, Wolfgang (red.). Bochum: Norbert Brockmeyer. 605-618.

Paczolay, Gyula. 1998a. Some Notes on the Theory of Proverbs. U: Europhras 97: Phraseology and Paremiology. Peter Durčo (red.). Bratislava: Akadémia PZ. 261-266.

Piirainen, Elisabeth. 2012. Widespread Idioms in Europe and Beyond. Toward a Lexicon of Common Figurative Units. New York - Washington, D.C. - Baltimore - Bern - Frankfurt Berlin - Brussels - Vienna - Oxford: Peter Lang. [Piir.]

Schemann, Hans. 2000. PONS Deutsche Redensarten. Stuttgart - Dusseldorf - Leipzig: Ernst Klett Verlag.

Sevilla Muñoz, Julia; Sevilla Muñoz, Manuel. 2005. La aplicación de las técnicas de la "traducción paremiológica" a las paremias populares relativas al vocablo pez en español, inglés y francés. Revista de Literaturas Populares. Año V. Número 2: 349-368. 
Singer, Samuel. 1995. Lexikon der Sprichwörter des romanisch-germanischen Mittelalters. Berlin - New York: Walter de Gruyter.

Šimunković, Ljerka. 2005. Fraseologia e paremiologia peschereccia in Dalmazia. U: Atti del $I^{\circ}$ Congresso Internazionale della Cultura Adriatica. Pescara (Italia), 6-9/10/2004 - Split (Croazia), 20-21/10/2004. Giammarco, Marilena; Sorella, Antonio (red.). Pescara: Fondazione Ernesto Giammarco. 112-133.

Županović, Šime. 1998. Hrvati i more. Knjiga 4: ribarska terminologija. Zagreb: AGM.

\section{RJEČNICl}

Allen, Robert. 2008. Allen's Dictionary of English Phrases. London - New York: Penguin Books.

Arthaber, Arturo. 1972. Dizionario comparato di proverbi e modi proverbiali in sette lingue (italiana, latina, francese, spagnola, tedesca, inglese, greca antica). Milano: Hoepli editore.

Bellostenecz, Joannes. 1740. Gazophylacium. Vol. I.: Gazophylacium seu Latino-Illyricorum Onomatum Aerarium. Vol. II.: Gazophylacium Illyrico-Latinum. Zagrabiae: Typis Joannis Baptistae Weitz. [pretisak Zagreb: Liber - Mladost, 1972]

Boerio, Giuseppe. 1856. Dizionario del dialetto veneziano. Venezia: Cecchini.

Boggione, Valter; Massobrio, Lorenzo. 2004. Dizionario dei proverbi. Torino: UTET. [Bogg. Mass.]

Capire l'antifona. Dizionario dei modi di dire con esempi d'autore. 1995. Turrini, Giovanna; Alberti, Claudia; Santullo, Maria Luisa; Zanchi, Giampiero (red.). Bologna: Zanichelli. [CDMDE]

Carbonell, Sebastian. 1983. Dizionario fraseologico completo italiano-spagnolo e spagnolo italiano. Parte spagnola-italiana. Milano: Ulrico Hoepli.

Cortelazzo, Manlio; Zolli, Paolo. 1999. Dizionario Etimologico della Lingua Italiana. [izd. 2, u jednome svesku, Cortelazzo, Manlio; Cortelazzo, Michele A. (red.)]. Bologna: Zanichelli. [1. izd. u 5 svezaka 1979-1988]

Daničić, Gjuro. 1871. Poslovice. Zagreb: Albrecht i Fiedler.

Detoni, Sereno. 2000 Proverbi della Dalmazia. Zara. Trieste: Edizioni Italo Svevo.

Dicionário da língua portuguesa. 2004. Porto: Porto Editora. [DLP]

Fronek, Josef. 1999. Anglicko-český, česko-anglický slovnik. Praha: LEDA.

Gran diccionario de uso del español actual. 2001. Sánchez, Aquilino (red.). Alcobendas-Madrid: SGEL. [GDUE]

Gulland, Daphne M.; Hinds-Howell, David. 2002. The Penguin Dictionary of English Idioms. London: Penguin Books. [Gull.]

Hansen, Renate et al. 1988. Hrvatsko-njemački frazeološki rječnik. Matešić, Josip (red.). Zagreb - München: Nakladni zavod Matice hrvatske - Otto Sagner. [HNjFR]

Lapucci, Carlo. 1969. Per modo di dire. Dizionario dei modi di dire della lingua italiana. Firenze: Valmartina Editore in Firenze. [LDMD] 
Lapucci, Carlo. 2007. Dizionario dei proverbi italiani. Firenze: Mondadori. [Lap.prov.]

Matković, Dinko. 2004. Rječnik frazema i poslovica govora Vrboske na otoku Hvaru. Jelsa: Ogranak Matice hrvatske Jelsa.

Menac, Antica; Fink-Arsovski, Željka; Venturin, Radomir. 2003. Hrvatski frazeološki rječnik. Zagreb: Naklada Ljevak. [MFV]

Menac, Antica; Vučetić, Zorica. 1995. Hrvatsko-talijanski frazeološki rječnik. [II. izd.]. Mali frazeološki rječnici. 10. Zagreb: Zavod za lingvistiku Filozofskog fakulteta. [MVHTF]

Mikić, Pavao; Škara, Danica. 1992. Kontrastivni rječnik poslovica. Zagreb: August CesarecŠkolska knjiga.

Miotto, Luigi. 1984. Vocabolario del dialetto veneto-dalmata. Trieste: LINT.

Paczolay, Gyula. 2002. European proverbs in 55 languages with equivalents in Arabic, Persian, Sanskrit, Chinese and Japanese. Hobart, Tasmania: De Proverbio.com. [Pacz.55L]

Pittàno, Giuseppe. 1992. Frase fatta capo ha. Dizionario dei modi di dire, proverbi e locuzioni. Bologna: Zanichelli.

PONS Standardwörterbuch Russisch-Deutsch. Deutsch-russisch. 2003. Stuttgart: Ernst Klett Sprachen. [PRDDR]

PONS Wörterbuch für Schule und Studium Ungarisch-Deutsch. 2002. Stuttgart: Ernst Klett Sprachen. [PWUD]

Quartu, Bruna Monica. 2001. Dizionario dei modi di dire della lingua italiana. Milano: Biblioteca Universale Rizzoli.

Redewendungen. Wörterbuch der deutschen Idiomatik. 1998. Herausgegeben von der Dudenredaktion. [3., überarbeitete und aktualisierte Auflage]. Mannheim - Leipzig - Wien - Zürich. [RWDI]

Rječnik hrvatskoga jezika. 2000. Šonje, Jure (red.). Zagreb: Leksikografski zavod Miroslav Krleža - Školska knjiga. [RHJ]

Schoretits, Ana; Probst, Eva. 2005. Prvo speci, pa reci. Kroatische Sprichwörter. Željezno - Eisenstadt: Hrvatsko kulturno društvo u Gradišću - Kroatischer Kulturverein im Burgenland.

Selene, Annarosa. 1990. Dizionario dei proverbi. Milano: Orsa Maggiore.

Senc, Stjepan. 1910. Grčko-hrvatski rječnik za škole. Zagreb: Kr. hrv.-slav.-dalm.-zem. vlada.

Simrock, Karl. 2003. Die deutschen Sprichwörter. Düsseldorf: Albatros.

Skarpa, Vicko. 1909. Hrvatske narodne poslovice. Šibenik: Hrvatske tiskare.

Sorge, Paola. 2001. Dizionario dei modi di dire della lingua italiana. Origine e significato delle frasi idiomatiche e delle forme proverbiali rare e comuni. Roma: Newton \& Compton Editori.

The Penguin Dictionary of Proverbs. 2000. Market House Books Ltd. Fergusson, Rosalind; Law, Jonathan (red.). [izd. 2]. London: Penguin Books. [PDP]

Wörterbuch Deutsch-Italienisch. Italienisch-Deutsch. 2001. Giacoma, Luisa; Kolb, Susanne (red.). Bologna - Stuttgart: Zanichelli - PONS Klett. [WDI] 


\section{MREŽNI IZVORI}

Большой толково-фразеологический словарь Михельсона. http://dic.academic.ru/dic.nsf/ michelson_old/ [BTFM] Datum posjeta: 18.4.2014.

Desiderius Erasmus. Adagiorum chiliades. AWOL The Ancient World Online. CORPUS CORPORUM: repositorium operum Latinorum apud universitatem Turicensem. http://www. mlat.uzh.ch/MLS/xanfang.php?tabelle=Desiderius_Erasmus_cps4 [EA] Datum posjeta: 15. 4. 2014.

Diccionario de dichos y refranes. Los diccionarios y las enciclopedias sobre el Académico. http://www.esacademic.com/dic.nsf/sp_sp_dichos_refranes/[DDR] Datum posjeta: 5. 4. 2014.

Gibbs, Laura. 2006. Latin Via Proverbs: 4000 Proverbs, Mottoes and Sayings for Students of Latin. http://latinviaproverbs.pbworks.com/ Datum posjeta: 3. 2. 2011.

Primerjava frazemovo živalih in rastlinah v slovenščini, slovaščini in ukrajinščini. 2013. Mladi za napredek Maribora. http://www.zpm-mb.si/attachments/sl/1163/OS_Slovenski_ jezik_Primerjava_frazemov_o_zivalih.pdf [PFŽR] Datum posjeta: 15. 4. 2014.

Proverbi e modi di dire sui pesci. http://parliamoitaliano.altervista.org/proverbi-e-modi-di-dire-sui-pesci/ [PMP] Datum posjeta: 12. 4. 2014.

Proverbi latini con traduzione. http:/www.pievedirevigozzo.org/07latino/proverbi/proverbi_p.htm [PLT] Datum posjeta: 12.4. 2014.

Refranero Multilingüe. Centro Virtual Cervantes. http://cvc.cervantes.es/lengua/refranero/ [RCVC] Datum posjeta: 10. 4. 2014.

Словари и энияилопедии на Академике. http://proverbs_ru_en.academic.ru/3120/ [Слов. Акад.] Datum posjeta: 12. 4. 2014.

Taylor, Archer. 1996. It is good fishing in troubled (muddy) waters. De Proverbio. Issue 3 \& 4: 1996. An electronic book. http://www.deproverbio.com/display.php? $\mathrm{a}=3 \& \mathrm{r}=32$ Datum posjeta: 8. 4. 2014. 


\section{ASTRATTO}

\section{IL LESSEMA PESCE NELLA FRASEOLOGIA DELLA LINGUA CROATA E DI ALTRE LINGUE EUROPEE}

Fin dai tempi antichi il lessema pesce è presente nella fraseologia croata e quella di altre lingue europee. Lo scopo di questo articolo è di analizzare alcune delle espressioni idiomatiche con tale lessema, che non di rado derivano da proverbi. Dal momento che spesso traggono origine dal greco antico e dal latino, si presta attenzione alla loro registrazione negli „Adagiorum chiliades“ di Erasmo da Rotterdam, in cui i proverbi, le massime e i modi di dire latini sono commentati e illustrati con esempi d'autore greci e latini, nonché della Bibbia. Tale raccolta di Erasmo è una testimonianza della tradizione paremiologica europea e poteva fungere da una delle fonti secondarie dei proverbi e modi di dire europei, che si sono diffusi in altre lingue per mezzo delle traduzioni. Oltre alle espressioni idiomatiche col lessema pesce, l'analisi comprende anche il modo di dire pescare nel torbido, col verbo che nella maggioranza delle lingue analizzate è derivato dal lessema pesce ed è frequentemente usato con il significato metaforico (ad es., fr. pêcher la nouvelle, it. pescare le informazioni, ted. die Information auffischen).

Parole chiave: lessema pesce, espressione idiomatica, proverbio, lingua croata, altre lingue europee 